\title{
Surgical Treatment of Monostotic Craino-Facial Fibrous Dysplasia: Changing the Narratives
}

\author{
I. O. Gbujie*, E. A. Dahillo, D. F. Fulorunso, B. E. Nwankwo, O. R. Quadri, B. I. Egbe, B. F. Bello, \\ F. M. Damtong, T. S. Ibekwe \\ Uath Gwagwalada, Nigeria \\ Email: *onyigbujie@yahoo.co.uk
}

How to cite this paper: Gbujie, I.O., Dahillo, E.A., Fulorunso, D.F., Nwankwo, B.E., Quadri, O.R., Egbe, B.I., Bello, B.F., Damtong, F.M. and Ibekwe, T.S. (2021) Paper Title. International Journal of Otolaryngology and Head \& Neck Surgery, 10, 49-59.

https://doi.org/10.4236/ijohns.2021.101006

Received: November 24, 2020

Accepted: January 26, 2021

Published: January 29, 2021

Copyright $\odot 2021$ by author(s) and Scientific Research Publishing Inc. This work is licensed under the Creative Commons Attribution International License (CC BY 4.0).

http://creativecommons.org/licenses/by/4.0/

(c) (i) Open Access

\begin{abstract}
Background: Fibrous dysplasia mainly presents in its monostotic form in the cranio-facial region with serious cosmetic disfigurement and functional derangement of the affected and adjacent structures putting both patient and the attending surgeon in great dilemma. Surgical treatment is the only rewarding and generally accepted treatment option, however, controversy over the surgical technique to be adopted still exists. While in the past, surgeons generally adopted conservative shaving or contouring technique, over the recent years, advocates of radical surgery are winning more disciples. Objective: To highlight the locally destructive, functionally degrading nature of a neglected or poorly excised (shaved) lesion in patients and highlight the outcome of total excision and surgical technique adopted to obviate the need for autologous bone grafting and two-staged surgery. Subjects and Method: We present case series of three patients with giant monostotic fibrous dysplasia of the maxilla, surgically treated in our Centre, who were part of a total of eight cases managed over the past fifteen years in our department of Ear, Nose and Throat-Head and Neck Surgery. The pre-operative clinical assessment, relevant investigations and post-operative outcome are presented. Our surgical technique is highlighted. All the patients had unilateral lesion of the maxilla with gross cosmetic and functional defects. Two of the patients had ischaemic (pressure) atrophy of the cheek soft tissue and skin leading to skin metaplastic changes including leukoplakia, hyperpigmentation. Post-operative follow-up showed satisfactory cosmetic outcome and significant reversal of malocclusion and dental anarchy. There was no recorded recurrence throughout the follow-up period ranging from four to eleven years. Nasal airway was re-established bilaterally in all the cases. Conclusion: Total or near total excision surgical technique with periosteal preservation is our treatment of choice in the management of monostotic cranio-facial fibrous dysplasia. Given the fact that the growth of the tumours often does not cease after puberty against
\end{abstract}


general belief, shaving or contouring technique should be relegated to the background. Our technique of no grafting which reduced cost and morbidity to the patient should be encouraged.

\section{Keywords}

Monostotic Fibrous Dysplasia, Fibro-Osseous Tumor, Total or Radical Excision, Autologous Bone Graft, Shaving or Contouring

\section{Introduction}

Fibrous dysplasia is a non-neoplastic bone tumour. Fibro-osseous tumour is used interchangeability by pathologists and clinicians universally to depict the same pathology. It is a genetically anchored developmental aberration of bone-forming mesechymal tissues with defective osteoblastic differentiation and maturation, resulting to the replacement of normal bony tissue by fibrous tissue of variable cellularity and immature woven bone [1]-[6]. It is as a result of post-natal mutation of GNASI gene which triggers the activation and proliferation of undifferentiated mesenchymal tissue. Generally, this lesion clinically presents in three forms namely Monostotic, polyostotic and polyostotic with endocrine dysfunction and skin hyperpigmentation (café-au-lait spots). This third form is also known as McCune Albright syndrome. It is worthy to note that a very small percentage of Cherubism which is a hereditary, autosomal dominant disorder, resulting from SH3BP2 gene mutation can present with a monostotic lesion [3] [6].

It is relatively uncommon in our region and worldwide has a prevalence of $1: 4000$ to $1: 10,000$ accounting for $7 \%$ of benign bone tumours. There is slight female preponderance. The monostotic form accounts for $70 \%$, polyostotic $27 \%$ and McCune Albright syndrome 3\% of all fibrous dysplasia. Cranio-facial region is involved in $27 \%$ of monostotic lesion and $50 \%$ of polyostotic lesion [3] [7] [8].

Monostotic craniofacial Fibrous dysplasia starts in the first and second decades of life, exhibits slow growth rate and generally believed to stop growing after puberty in the third decade [1] [3] [6]. However, several reports documented lesions manifesting rapid growth in adult life [9] [10].

Clinically, there are no specific symptoms and signs of the tumour. Its manifestation is dependent on the particular structure and organ involved. Generally, it presents a painless swelling of the involved cranio-facial bone, with its attendant aesthetic deformity. Extension into nasal fossa, alveolus, orbit and optic nerve, may result in nasal blockage, malocclusion and dental anarchy, as well as visual impairment.

Grossly, the tumour appears variable in consistency, depending on the tissue composition [2] [4]. It may be, gritty, hard in a portion, firm in a largely fibrous component or soft when cystic degeneration has taken place. It is well circum- 
scribed, with a clear cleavage line from normal bone and periosteum but is devoid of a true capsule. There is no extension to adjacent bones but compresses, displaces and distort such bones and structures.

While administration of bisphosphonates has been found to be reasonably beneficial in slowing down or arresting growth in polyostotic fibrous dysplasia, it is of no value in monostitic lesions [8] [9]. Thus, treatment is principally surgical. However, there is serious controversy over the surgical strategy; radical surgery (total or near total excision) or conservative surgery (shaving or contouring). Those in favour of conservative approach argue that the tumour grows slowly and cease at the end of skeletal maturity and hence shaving to address the cosmetic deformity is what is needed. Also, they argue that radical surgery early in life before cranio-facial skeletal maturation negatively affects cranio-facial skeletal development as well as damages permanent dentition [7] [11] [12] [13] [14] [15]. Proponents of radical approach based their stand on the fact that functional preservation and restoration should be of primary consideration over aesthetics and that conservative surgery does not prevent or restore functional destruction by the lesion. Also, the tumour has been observed to have variable growth behavior in various age groups and individuals, so its destructive tendencies may be unpredictable if left to linger for a long period [11] [12] [15] [16] [17]. Furthermore, the possibility of malignant transformation calls for a more radical approach to surgical treatment [18] [19] [20].

The indication for prophylactic optic nerve decompression is highly discouraged as the risk to the healthy nerve is very high, however, the procedure is recommended if there is gradual visual loss or sudden visual loss of less than one week. Visual recovery is known to be impossible if decompression is performed in the second week following sudden visual loss [16]. Surgeons generally adopt vascularized autologous bone grafts from the calvarium, ribs, fibula or iliac crest to reconstruct the cranio-facial bone defects following radical excisions.

In the light of the above pros and cons, we adopted a radical approach to the management of all the eight patients with monostotic craniofacial fibrous dysplasia that presented to our department over a fifteen year period. Our surgical technique and surgical outcome of three giant tumours are here presented to buttress our choice and recommendation for radical surgery as the best option in managing the disease.

\section{Highlights of Our Surgical Technique}

All our cases are done under general anaesthesia.

Giant tumours are approached using lateral rhinotomy incision while smaller lesions are excised via wide Caldwell-luc incision over the canine fossa. The periosteal layer and normal bone over the mass is carefully elevated and preserved. The tumour is removed piece meal using luc's-forceps, osteotomes, electric drill with cutting burs and bone curette as need arises. Extreme care is taken to avoid damage and removal of loose teeth which may be anchored only by a thin plate 
of alveolar bone covered by muco-periosteum or muco-periosteum-osteal plate alone. Damage to orbital periosteum is avoided in the face of complete destruction of the bones of roof of the antrum by the lesion. Following complete or near complete tumour removal, obstruction of the nasal airway is appropriately addressed. The antero-lateral wall of the maxillary defect is closed by apposition of the periosteal flap or osteo-periosteal, after trimming to achieve a tense desired contour. Shaving of adjacent normal but distorted bones is undertaking for facial cosmetic correction. The surgical cavity is packed with ribbon guaze impregnated with liquid paraffin and $10 \%$ betadine solution and left in-situ for about seven days. With these steps, we have not found any need for grafting and the procedures are single-staged.

Following these steps, the cosmetic appearance of the face achieved on the table remains unaltered in the post-operative period. The periosteum and any thin plate of normal bone left attached to it strengthens over weeks after surgery due to new normal bone formation from the periosteum. This also occurs in the alveolar region, strengthening the loose teeth and the dental arch. Over time, remodeling of the distorted alveolus and dental anarchy become significantly spontaneously corrected.

\section{Case Reports}

We present three patients with the most advanced disease from our series of eight patients with a long follow-up period of four to eleven years post -surgery, to dispel the old concept in the tumour growth behaviour and highlight poor surgical outcome with old modality of surgical treatment, as well as very satisfactory functional and cosmetic outcome, following total or near total surgical tumour excision. The second and third cases in these series had previously had conservative surgical treatment (surgical tumour shaving) months before presenting to us, with cosmetic and functional complications and rapidly increasing tumour growth despite crossing the bone growth maturation age. All patients in the series gave their informed consent for the clinical records to be used for for this publication.

\subsection{Case 1}

A 14 year old female presented 11 years ago with a history of slowly progressive, painless right cheek swelling of two years duration. The mass exhibited rapid growth in the last six months prior to presentation causing obstruction of lower visual field ipsilaterally, with progressive bilateral nasal blockage and epistaxis in the last few days. There was no similar swelling in other parts of the body.

Physical examination revealed a huge spherical mass, non-tender, measuring about $10 \times 12 \mathrm{~cm}$, with mixed consistency of bony, soft and gritty nature. It involved the entire right maxilla, with intra-oral extension, alveolar distortion, intra-nasal extension displacing the septum into the left nasal cavity and occluding both nasal cavities. There was slight upward displacement of the orbit (Figure 1). 


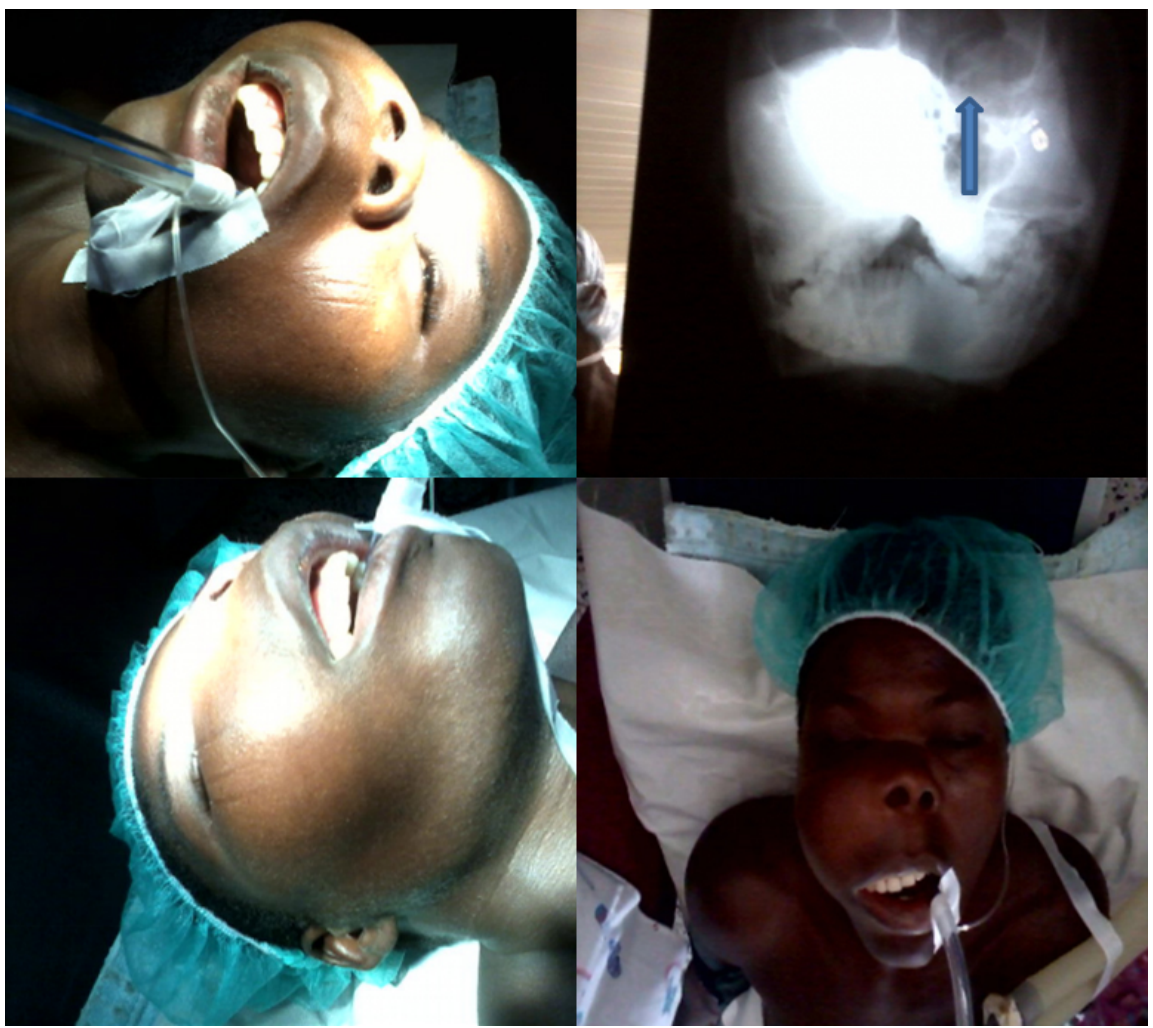

Figure 1. Case NO.1, pre-operative clinical photograph and plain xry of maxilla. Arrow points to the upward displaced floor of orbit on the affected side.

Plain xry of the paranasal sinuses showed large tumour with mixed opacity, some areas showing glass ground appearance. Adjacent bones and structures though compressed, were not invaded by the mass. At surgery, the mass had clear well circumscribed margins, fibrous or fibro-osseous with some areas of cystic degeneration.

Surgical excision via a lateral rhinotomy approach was done, adhering to the surgical technique outlined above (Figure 2).

She had a cosmetically stable and satisfactory post-operative outcome. Follow up for eleven (11) years without sign of recurrence was observed (Figure 3). Histology report indicated the mass to be fibro-osseous tumour.

\subsection{Case 2}

A 33 year old house wife presented four years ago with a history of swelling of right upper jaw of five years duration prior to presentation. The swelling was painless and slowly progressive, with gross facial deformity, and dental disorganization and dental loss. There was bilateral nasal blockage, mucopurulent nasal discharge and intermittent epistaxis. One year prior to presentation, she presented to a maxillo-facial department of another Hospital where conservative surgical excision of the mass was done. This was shortly followed by rapid growth of the mass, with increased disfigurement of the face, facial numbness, epiphora, and ulceration of the cheek skin over the mass. 


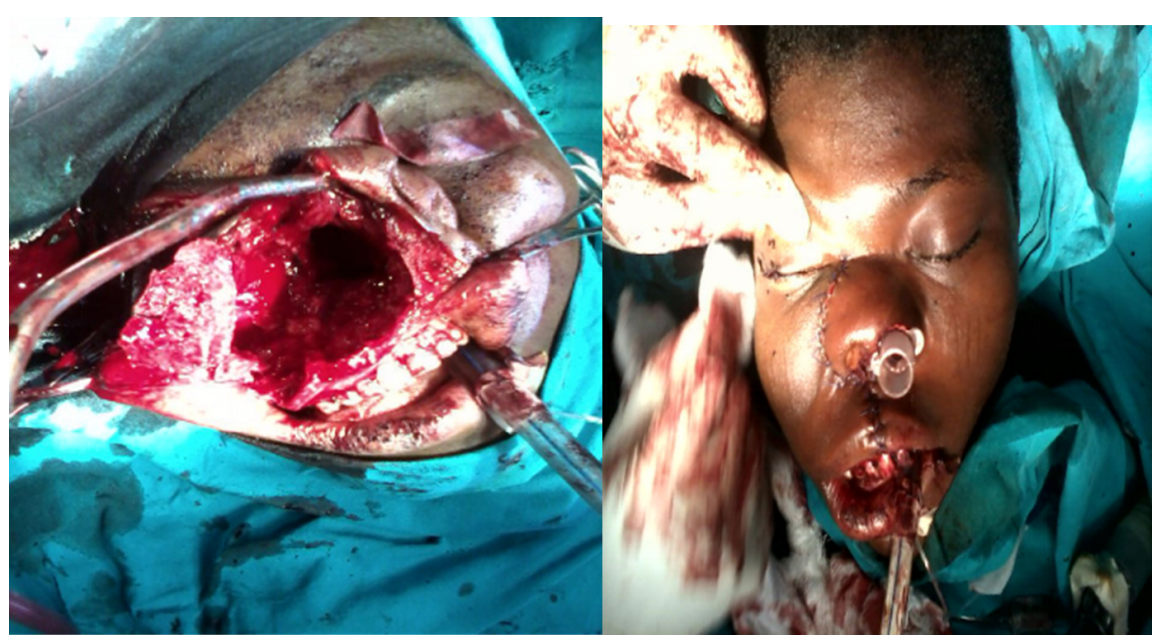

Figure 2. Case NO.1, Surgical cavity after total excision and cosmetic contour following surgical closure.

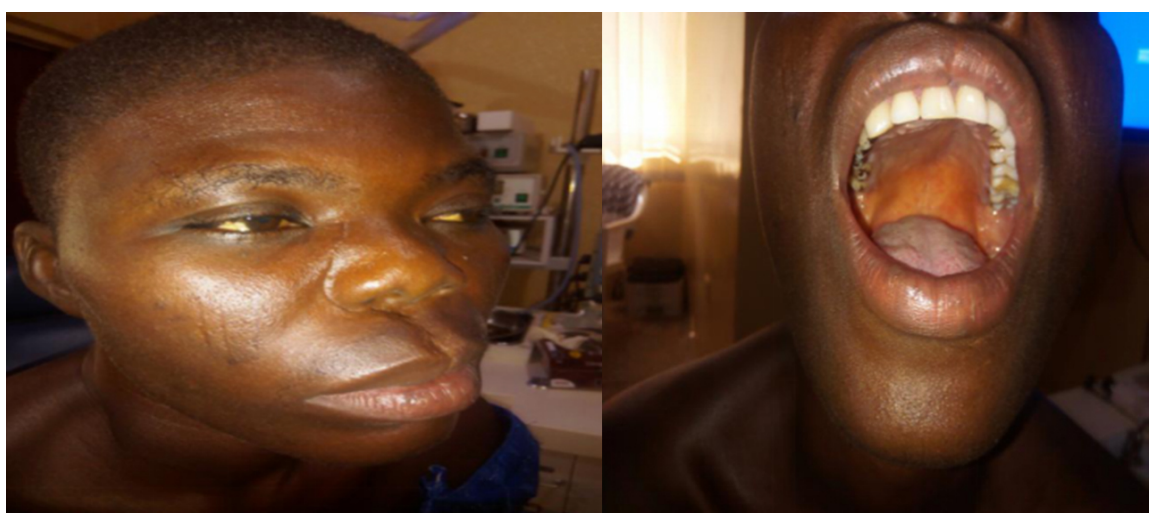

Figure 3. Case NO.1 showing the $11^{\text {th }}$ Year post surgery photographs; showing satisfactory facial contour, palato-alveolar bone remodeling, reversal of malocclusion.

Clinical examination revealed gross monstrous facial deformity, with a huge right maxillary tumour displacing the orbit upward and laterally, dental anarchy and mal-occlusion, intra oral extension. There were leukoplakia, hyperpigmentation and ulceration of the overlying cheek skin. Right nasal cavity was completely occluded, with the septum displaced and plastered to the lateral wall of the left nasal fossa (Figure 4).

Plan radiograph of the paranasal sinuses showed extension of the mass into ethmoidal and sphenoidal sinus areas.

Total tumour excision was carried out via extended lateral rhinotomy and cosmetic deformity tackled as outlined in our technique above. The ulcerated area of the check with the surrounding dysplastic skin was excised and the defect primarily closed using advancement cheek flap. Nasal airway was achieved by septal manipulation (Figure 5). She had a satisfactory surgical cosmetic outcome. Follow-up over four year post-operative period has not detected any sign of recurrence clinically and has reunited with her husband who abandoned her at the heat of the health challenge. Surgical pathological findings included: 


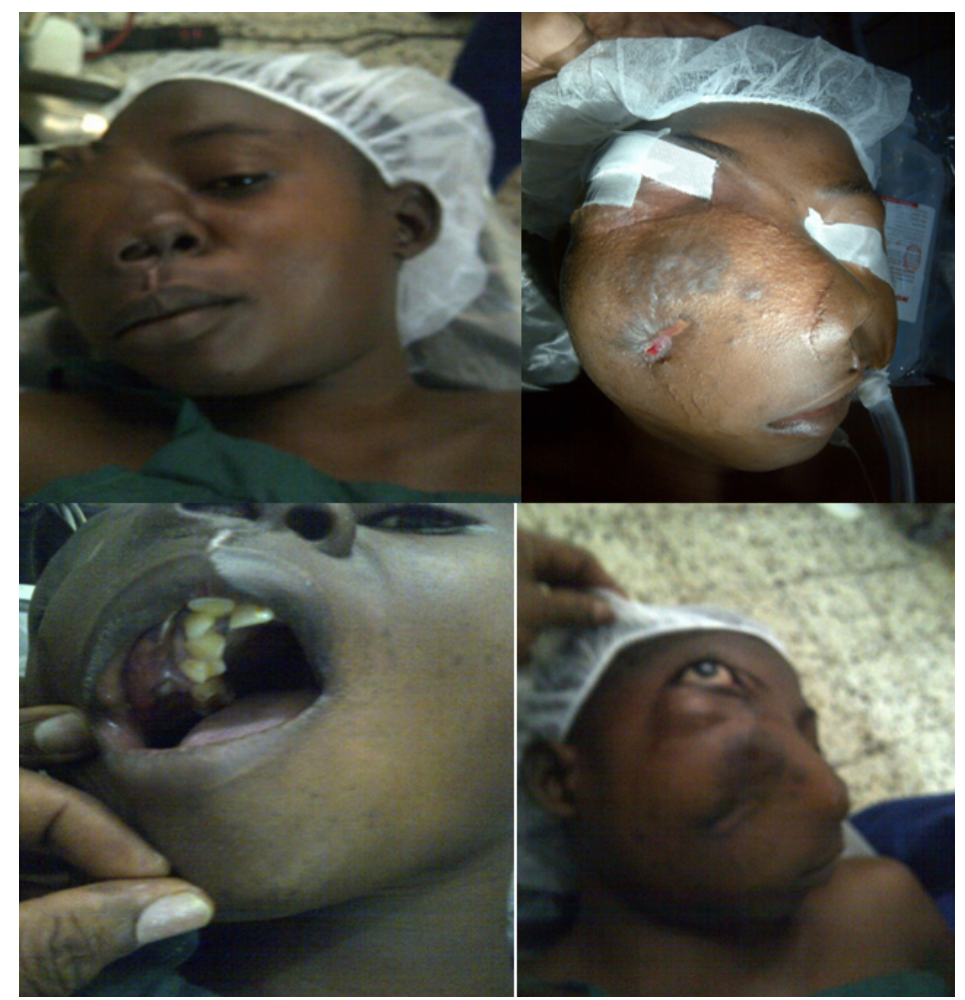

Figure 4. Pre-operative photographs of Case No.2. Note: Scare and chronic ulceration and skin changes, surgical Scare and depression caused by previous conservative surgery, dental anarchy, gross facial deformity, marked upward and lateral displacement of the orbit.

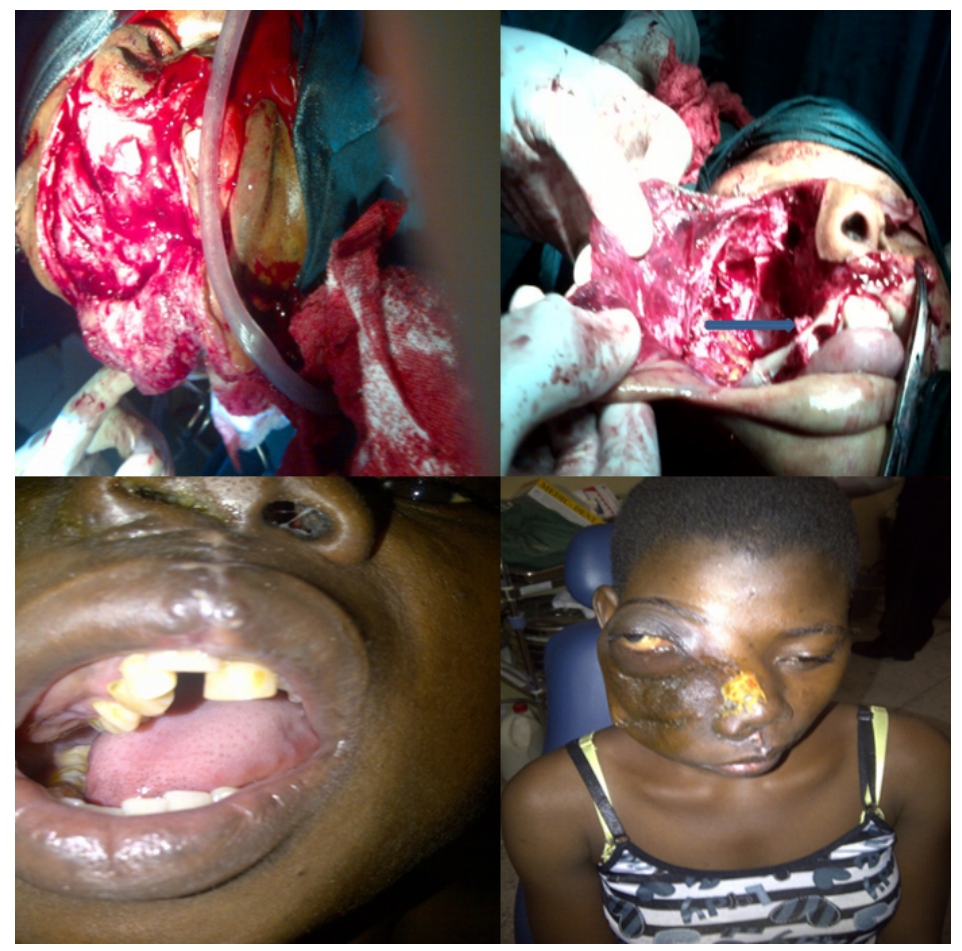

Figure 5. Photographs of Case No.2 showing: tumour following facial flap elevation, cavity left after complete tumour excision, patient's appearance on the $14^{\text {th }}$ day post-operative period. Arrow shows a loose tooth anchored by mucoperiosteum. 
1) Well circumscribed maxillary fibrous/fibro-osseous mass, with well delineated borders, areas of cystic degeneration.

2) Compression of normal maxillary bone into a tin plate of egg shell-like or biscuit bone firmly attached to overlying periosteum or mucoperiosteum.

3) Compression and displacement of adjacent bones without breaching or crossing of suture lines.

4) Compression atrophy of over-lying soft tissue of the cheek, including muscles of facial expression, masseter and cheek adipose tissue.

5) Ulceration, dysplasia of the soft tissue and skin due to ischaemia from pressure compression by the mass.

Histology analysis of the surgical specimen confirmed the lesion to be fibrous dysplasia in line with the result of initial result from the first hospital.

\subsection{Case 3}

A nineteen year old female patient, who incidentally is a younger sibling of case no. 2 above, presented also 4 years ago, some months after treating the elder sibling, with a six year history of painless progressive right cheek swelling. There was complaint of serious facial deformity, nasal blockage, mucopurulent rhinorrhea and epiphora on the same right side.

Clinical examination showed, a huge, spherical mass, non-tender, hard, measuring about $10 \times 12 \mathrm{~cm}$, involving the entire maxilla. There was compression and displacement of the zygoma with healed superficial scar over the cheek mass. The lower $1 / 3$ of the visual field was obscured by the mass, with non-axial proptosis and lateral displacement of the orbit but intact visual acuity. There was obliteration of the right nasal cavity with septal displacement to the left as well as distortion of the hard palate and dentition disorganization (Figure 6).

Similarly, patient underwent total excision using Weber-Fergussion incision, observing the technical steps outlined above. Surgical findings are identical with those of Case 2 above, except for absence of ulceration of skin and soft tissue. Follow-up over the years showed significant cosmetic restoration, dentition strengthening and improvement (Figure 7) Histology report indicated the mass to be fibrous dysplasia.

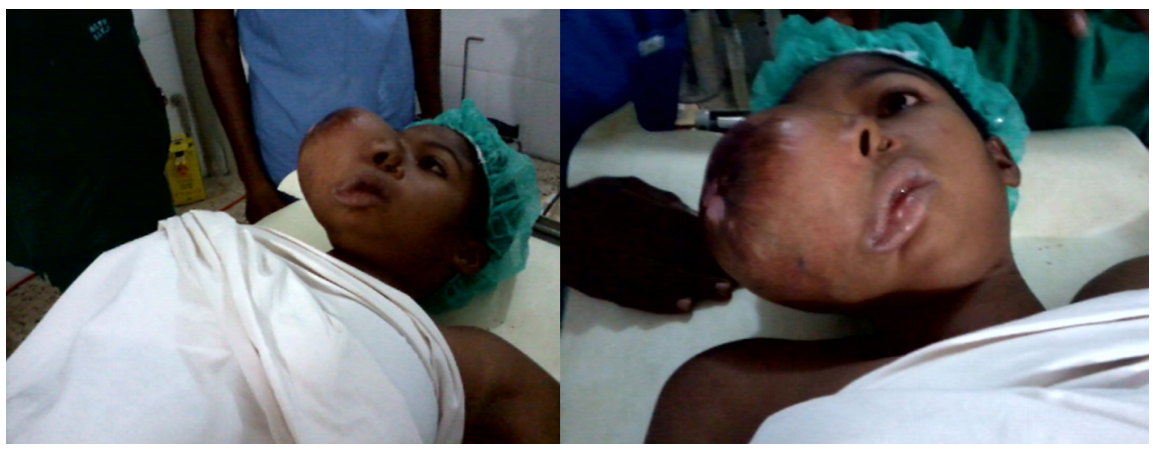

Figure 6. Pre-operative photograph of Case No.3 Note: Giant tumour, blocking ipsilateral visual field, compression and displacement of left nose, leukoplakia, hyperpigmentation of the cheek skin. 


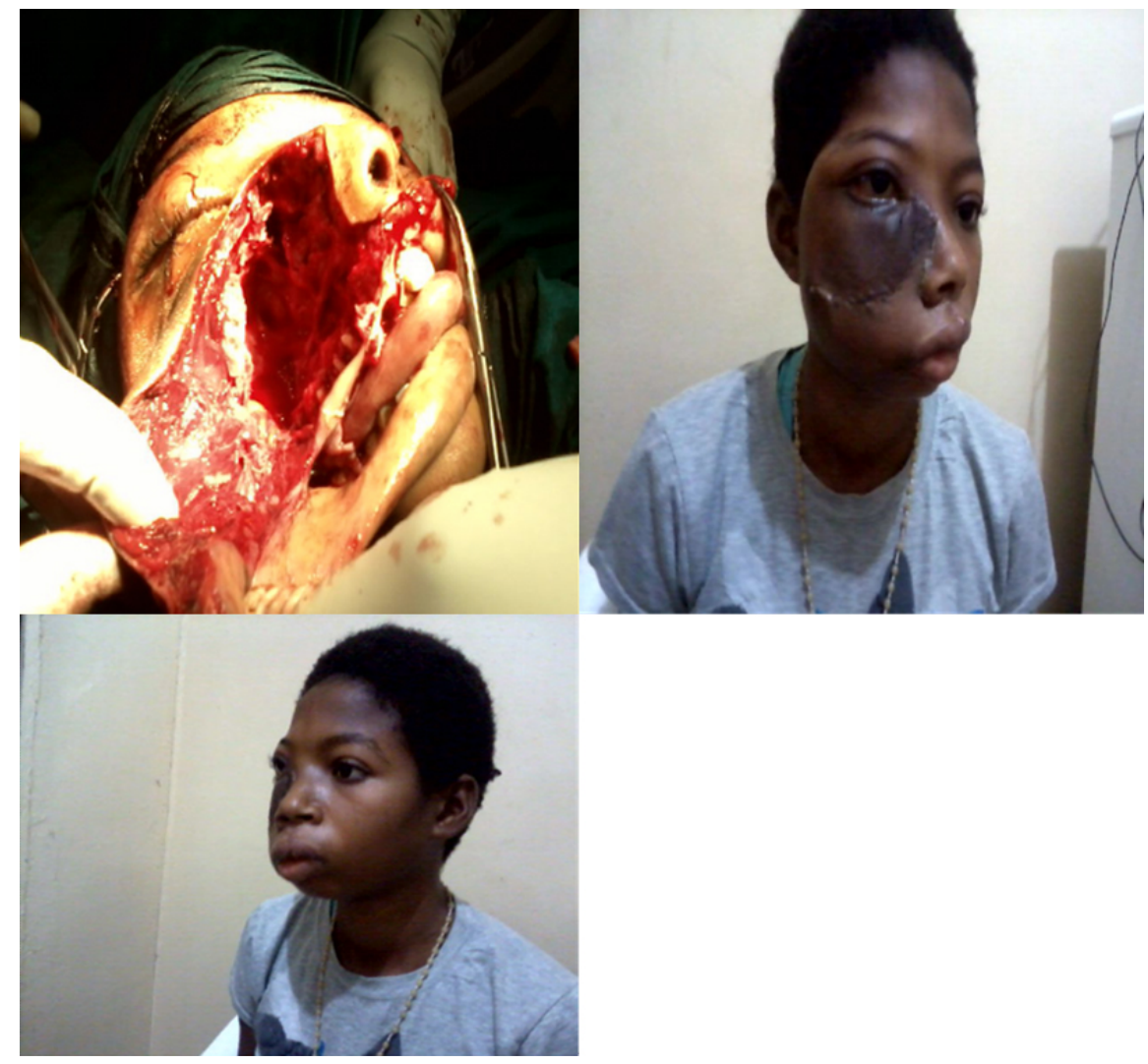

Figure 7. Photographs of Case No.3 showing the cavity after complete tumour excision and patient's appearance on the $21^{\text {st }}$ day post-operative period.

\section{Discussion}

Out of the eight cases that presented to us, only two where males aged sixteen and 18 years. This is in agreement with female preponderance reported in the literature [2] [3] [15]. All the case series are female. The three cases under review showed that the patients were in the second and third decades of life with fibrous dysplasia that displayed progressive growth with gross deformities, destruction and disruption of function. Even the last two patients who were in the third decade of life had tumour growing progressively contrary to old concept that fibrous dysplasia stops growing at the end of growth spot (18 to 21 years). There was no relationship with full skeletal maturity (closure of growth plate) or puberty in these series. The aesthetic complication and functional disruption of the nose, vision and visual field, dental occlusion and alignment that were present in all the three cases, calls for early radical surgical treatment, as the only lasting panacea for prevention and treatment of these complications of Monostotic craniofacial fibrous dysplasia. We are of the opinion that the argument that radical and early surgical treatment jeopardizes permanent dentition is not a convincing reason, since neglected or poorly treated (conservative approach) will eventually destroy these permanent teeth as evident in the star cases above.

Furthermore, the last two cases is a clear evidence of uselessness of conservative surgical shaving as a treatment option, having failed to arrest further growth 
of the tumour and its complications. After four to fifteen (4 - 15) years of follow-up, we have not recorded any recurrence in our series of eight patients so far managed and no malignant transformation.

It is worthy of note that the cosmetic outcome of the case no. 2 and case no. 3 above after total surgical excision was far better than the outcome of conservative surgical technique earlier done in the first Hospital. Thus in terms of permanent or lasting functional restoration, aesthetic outcome, prevention of recurrence and malignant transformation, radical surgical excision is quite superior to conservative approach.

Literature search did not reveal any report dealing with the technique of single-staged total tumour excision without bone grafting, neither did we see a description of periosteal handling to deal with cheek cosmetic deformity.

Our simple novel technique of periosteum preservation and refashioning offers a cost effective and morbidity-reducing surgical strategy which did not compromise the cosmetic outcome. A two stage surgical procedure is costlier and carries more morbidity. We, also, recommend the technique for mandibular lesions with a micro pin and plate to hold the two ends of the bone after excision of the tumour.

\section{Conclusion}

Total or near total excision surgical technique with periosteal preservation is our treatment of choice in the management of monostotic cranio-facial fibrous dysplasia. Given the fact that the growth of the tumour often does not cease after puberty against general belief, surgical shaving or contouring technique should be de-emphasized. Our technique of no grafting which reduced cost and morbidity to the patient should be encouraged.

\section{Conflicts of Interest}

The authors declare no conflicts of interest regarding the publication of this paper.

\section{References}

[1] Nicolai, P. and Castelnuovo, P. (2010) Benign Tumours of Sinonasal Tract. In: Cummings Otolaryngology, Head and Neck Surgery, Mosby, Missouri, 725-726.

[2] Draf, W. (2008) Fibrous Dysplasia of the Nose and Paranasal Sinuses. In: Scott-Brown's Otolargyngology, Head and Neck Surgery, 7th Edition, CRC Press, Boca Raton, 1521-1522.

[3] Bhattacharya, S. and Mishra, R.K. (2015) Fibrous Dysplasia and Cherubism. Indian Journal of Plastic Surgery, 48, 236-248. https://doi.org/10.4103/0970-0358.173101

[4] Andrew, E. and Rosenberg, M.D. (1994) Bone Tumours and Tumour-Like Lesions. In: Pathological Basis of Diseases, 5th Edition, Saunders, Philadelphia, 1241-1243.

[5] Kauda, M., Yalki, I., Murakami, Y., Hasengawa, Y. and Kanki, T. (2002) Monostotic Fronto-Orbital Fibrous Dysplasia with Convulsion-Case Report. Neurologia Medicochirugica, 42, 36-39. https://doi.org/10.2176/nmc.42.36

[6] Abdel-wanis, M. and Tsuchiya, H. (2002) Melatonin Deficiency and Fibrous Dysplasia: Might a Relation Exist? Medical Hypothesis, 59, 552-554. 
https://doi.org/10.1016/S0306-9877(02)00251-7

[7] Petrocelli, M. and Kretschmer, W. (2014) Conservative Treatment and Implant Rehabilitation of the Mandible in a Case of Craniofacial Fibrous Dysplasia: A Case Report. Journal of Oral and Maxillofacial Surgery, 72, 902-906. https://doi.org/10.1016/j.joms.2014.01.020

[8] Mäkitie, A.A., Törnwall, J. and Mäkitie, O. (2008) Bisphosphonate Treatment in Craniofacial Fibrous Dysplasia-A Case Report and Review of the Literature. Clinical Rheumatology, 27, 809-812. https://doi.org/10.1007/s10067-008-0842-Z

[9] Boyce, A.M., Kelly, M.H., Brillante, B.A., Kushner, H., Wientroub, S., Riminucci, M., et al. (2014) A Randomized, Double Blind, Placebo-Controlled Trial of Alendronate Treatment for Fibrous Dysplasia of Bone. The Journal of Clinical Endocrinology and Metabolism, 99, 4133-4140. https://doi.org/10.1210/jc.2014-1371

[10] Park, B.Y., Cheon, Y.W., Kim, Y.O., Pae, N.S. and Lee, W.J. (2010) Prognosis for Craniofacial Fibrous Dysplasia after Incomplete Resection: Age and Serum Alkaline Phosphatase. International Journal of Oral and Maxillofacial Surgery, 39, 221-226. https://doi.org/10.1016/j.ijom.2009.12.008

[11] Valentini, V., Cassoni, A., Marianetti, T.M., Terenzi, V., Fadda, M.T. and Iannetti, G. (2009) Craniomaxillofacial Fibrous Dysplasia: Conservative Treatment or Radical Surgery? A Retrospective Study on 68 Patients. Plastic and Reconstructive Surgery, 123, 653-660. https://doi.org/10.1097/PRS.0b013e318196bbbe

[12] Chen, Y.R. and Noordhoff, M.S. (1990) Treatment of Craniomaxillofacial Fibrous Dysplasia: How Early and How Extensive? Plastic and Reconstructive Surgery, 86, 835-844. https://doi.org/10.1097/00006534-199011000-00002

[13] Valentini, V., Cassoni, A., Terenzi, V., Della Monaca, M., Fadda, M.T., RajabtorkZadeh, O., Raponi, I., Anelli, A. and Iannetti, G. (2017) Our Experience in the Surgical Management of Craniofacial Fibrous Dysplasia: What Has Changed in the Last 10 Years? Acta Otorhinolaryngologica Italica, 37, 436-443.

[14] Bowers, C.A., Taussky, P. and Couldwell, W.T. (2014) Surgical Treatment of Craniofacial Fibrous Dysplasia in Adults. Neurosurgical Review, 37, 47-53. https://doi.org/10.1007/s10143-013-0500-z

[15] Béquignon, E., Cardinne, C., Lachiver, X., Wagner, I., Chabolle, F. and Baujat, B. (2013) Craniofacial Fibrous Dysplasia Surgery: A Functional Approach. European Annals of Oto-Rhino-Laryngology, Head and Neck Diseases, 130, 215-220. https://doi.org/10.1016/j.anorl.2012.07.005

[16] FredericoFigureiro, M., Denadai, R., Znardo, D., et al. (2013) Conservative or Radical Approach for Craniofacial Fibrous Dysplasia.

[17] Wang, Y., Sun, G., Lu, M. and Hu, Q. (2015) Surgical Management of Maxillofacial Fibrous Dysplasia. Journal of Oral and Maxillofacial Surgery, 53, 336-341. https://doi.org/10.1016/j.bjoms.2015.01.004

[18] Valentini, V., Cassoni, A., Marianetti, F. and Lannetii, G. (2007) Reconstruction of Craniofacial Defect Using Autologous Bone Grafts: A Retrospective Study of 233 Patients. Journal of Craniofacial Surgery, 18, 953-958. https://doi.org/10.1097/scs.0b013e3180690123

[19] Sadeghi, S.M. and Hosseini, S.N. (2011) Spontaneous Conversion of Fibrous Dysplasia into Osteosarcoma. Journal of Craniofacial Surgery, 22, 959-961. https://doi.org/10.1097/SCS.0b013e31820fe2bd

[20] Yabut, S.M., Kenan, S., Sissons, H.A. and Lewis, M.M. (1988) Malignant Transformation of Fibrous Dysplasia. A Case Report and Review of the Literature. Clinical Orthopaedics and Related Research, 228, 281-289.

https://doi.org/10.1097/00003086-198803000-00046 